\title{
Anti-exceptionalism about Logic Introduction
}

\author{
Ole Hjortland
}

Logic has traditionally played a foundational role in many epistemological programmes. But in order to fulfil this role, logic has been given a privileged epistemological status: it is self-evident, wholly a priori, or epistemologically analytic. This exceptional status of logic was famously challenged in W. V. Quine's "Two Dogmas of Empiricism". Logic, he concluded, is in principle no less revisable than the natural sciences. Contemporary antiexceptionalists agree with Quine that logical theories can be revised, but often disagree with his naturalist assumptions. Recent work by Graham Priest, Gillian Russell, Timothy Williamson, and others has attempted to replace logic's exceptional epistemology with a form of theory-choice more akin to that of other sciences.

This special issue is based on the papers presented at a workshop at the University of Bergen, entitled 'Logic as science'. We are very grateful to the participants and audience at the workshop, and to the Research Council of Norway for generous funding through the four-year project 'Anti-Exceptionalism About Logic' (2016-2021). 